\title{
Modeling Market Shares of Competing (e)Care Providers
}

\author{
Jan Van Ooteghem, Tom Tesch, Sofie Verbrugge, Ann Ackaert, Didier Colle, \\ Mario Pickavet, Piet Demeester
}

\author{
Ghent University - IBBT, Dept. of Information Technology (INTEC), \\ G. Crommenlaan 8 bus 201, 9050 Gent, Belgium \\ tel: +32 933 14900, fax: +32 93314899 \\ \{jan.vanooteghem, et al.\}@intec.ugent.be
}

\begin{abstract}
In order to address the increasing costs of providing care to the growing group of elderly, efficiency gains through eCare solutions seem an obvious solution. Unfortunately not many techno-economic business models to evaluate the return of these investments are available. The construction of a business case for care for the elderly as they move through different levels of dependency and the effect of introducing an eCare service, is the intended application of the model. The simulation model presented in this paper allows for modeling evolution of market shares of competing care providers. Four tiers are defined, based on the dependency level of the elderly, for which the market shares are determined. The model takes into account available capacity of the different care providers, in- and outflow distribution between tiers and churn between providers within tiers.
\end{abstract}

Keywords: eHealth, Techno-economics, Churn, Capacity modeling

\section{Introduction}

Most OECD countries, particularly those in the EU and Japan, will have to face the challenges raised by their ageing populations in the next decades [1]. It is a widely held belief that the introduction of ICT based eHealth initiatives to improve the efficiency of care provisioning could lead to both a reduction in cost and an improvement in overall standard of living for the elderly. For several years many initiatives have been taken to explore the technical and social implications of a wide variety of such eCare schemes [2][3]. Still large-scale rollouts have been lacking due to the absence of convincing business models.

The work presented in this paper is part of the IBBT TranseCare project [4], a research project aimed at developing ICT support tools and services for an eCare platform. It encompasses diverse fields including social, technical, economic and legal contexts. A custom configurable eCare platform has been developed within the project that connects to the users' television through the Internet, and allows for 
2 Jan Van Ooteghem, Tom Tesch, Sofie Verbrugge, Ann Ackaert, Didier Colle, Mario Pickavet, Piet Demeester

video-telephony with a professional care help-desk, other users of the eCare system and informal caregivers using an instant messaging client on their PC.

Within the IBBT TranseCare project a tool for techno-economic evaluation of the envisaged eCare platform will be elaborated, aimed at to value network [5] and multiactor analysis. This paper is a first step in this work, and focuses on market share forecasting for competing care services. The model takes into account different levels of dependency (and required care) of the elderly population. Estimating the influence of demographic evolution and current/future capacity limitations in high-dependency care provision facilities can help formulating an eCare case towards governmental agencies, insurance companies or private investors as to how much and how soon to invest in eHealth.

The paper first introduces the conceptual framework of the model and provides definitions for the used concepts. Next an intuitive overview is given of how the model functions, followed by simulation results based on the Flemish situation. Finally we end this paper with some conclusions and future work.

\section{Conceptual framework and model mechanisms}

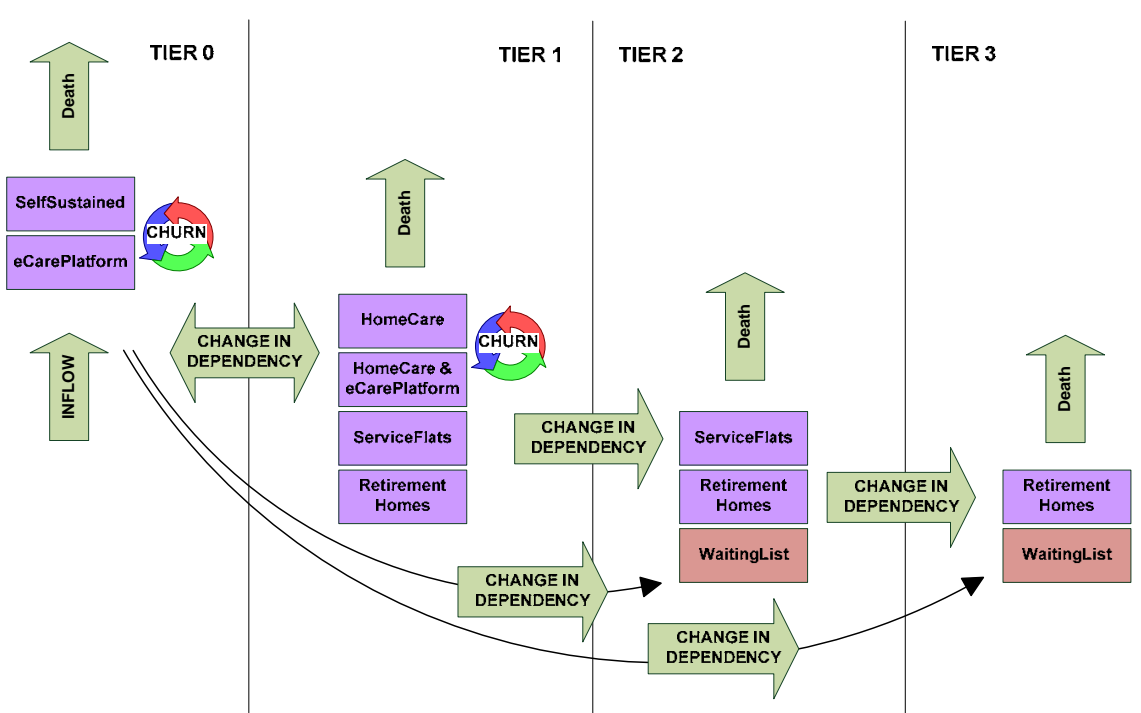

Fig. 1. Graphical representation of the developed market share model 


\subsection{Definitions}

A number of concepts need to be defined before the model per se can be introduced. First of all, four tiers representing different dependency levels of the elderly are explained. In normal situations, the level of dependency increases on ageing. But at times of life shed events (death of partner, illness, accidents, etc), a deterioration in health can cause suddenly a large increase in dependency.

- Tier 0 contains those elderly in good condition for whom no extra help is required.

- Tier 1 elderly require (some) external attention and care, but to such a limited extent that they can stay in their own homes.

- Tier 2 represents the elderly requiring extended external attention, and for whom staying in their private homes is therefore impossible.

- Tier 3 elderly require near constant (medical) attention, which only a retirement home can provide.

In these different tiers, competing care providers can be active. The context of these different care providers is defined below. Although not all categories reflect real professional care situations, these definitions allow for uniform modeling of the total envisaged population.

- SelfSustained (SS) elderly are those people still living in their private homes which do not need (professional) care.

- eCarePlatform (eCP) subscribers do not need (professional) homecare but have chosen to equip themselves with an eCarePlatform to facilitate interaction with informal caregivers (e.g. family) or to subscribe to additional services.

- HomeCare (HC) is on-demand supportive care provided in the patient's home by professionals (e.g. health care, cleaning, etc).

- HomeCare augmented with eCarePlatform (HC+eCP) is professional homecare facilitated by an eCarePlatform (with more eCare functionalities compared to the platform described above).

- Service Flats (SF) or assisted living facilities provide adapted living facilities for elderly who need already a certain level of continued care or assistance.

- Retirement Homes (RH) are multi-residence housing facilities intended for highest- level dependency elderly needing around the clock professional care.

Next to the six care providers, we also foresee a WaitingList (WL) reflecting the amount of high-dependent elderly who cannot receive adequate care at the time of need, due to capacity limitations in service flats and retirement homes.

\subsection{General Model Concept}

The model is organized around an inflow of customers. A person becomes a part of the scope of the model as soon as he/she turns 60. The model represents 4 tiers of dependency levels numbered 0 to 3 . A change in dependency makes the people move to higher tiers. This can happen gradually or a life shed event can make people move from Tier 0 to Tier 2 or even Tier 3. A potential backward move is only possible 
4 Jan Van Ooteghem, Tom Tesch, Sofie Verbrugge, Ann Ackaert, Didier Colle, Mario Pickavet, Piet Demeester

between Tier 1 and Tier 0 (e.g. after a hospital stay, temporary care can be needed). As customers move into a tier (either from outside the model by turning 60 or from another tier), they are distributed over the available competing providers in this tier. This allocation is based mainly on the current market shares of the providers, corrected by an elasticity (based on offered quality) and limited by capacity. Additionally within Tier 0 and Tier 1, we allow churn (level of customers switching of care provider within the same tier) as people could want to subscribe to the eCarePlatform to bridge certain temporary life situations. Churn is based on a different elasticity and limited by available capacity. People leave a certain tier by moving to a higher level of dependency, or by death. This can be seen in Fig. 1.For a more formal mathematical description of the churn and inflow sub models, please refer to [6].

\subsection{Inflow and Inter Tier Flow Distribution}

The flow distribution system starts from the assumption that customers are allocated according to existing market shares. In other terms if a provider has 30 percent of the market, he should get 30 percent of the inflow of new customers. This would lead to perfectly static market shares. The inflows are therefore modified based on the value offered (perceived quality divided by normalized price) and inflow value elasticity. The inflow value elasticity links the relative change in offered value to the change in percentage of the inflow. An inflow value elasticity of 2 means that if a player offers 10 percent more value than the average of all the providers he should receive 20 percent more customers compared to what he would be entitled to, based purely on his market share. Using this modeling scheme we can benchmark the value offered by a provider by comparing it to the weighted average of the value offered by competition (weighted by market share).

\subsection{Churn}

The churn mechanism is very similar to the flow distribution system. The main difference lies in the definition of the elasticity used. The employed churn value elasticity is defined as the change in market share of a provider relative to the value offered. In other terms a churn value elasticity of 0.5 signifies that if a provider offers a 10 percent better value than the average on the market, his market share should increase with 5 percent. The weighted average value offered has to be used to guarantee that the sum of the churn flow will amount to zero.

\subsection{Capacity}

The capacity model limits the total inflow into a tier to the total available capacity of a tier at that moment in time. This limited flow is then distributed using the inflow and churn model using an iterative process that takes one step less than the number of providers in a tier. With each step (in a capacity limited situation) at least 1 provider 


\section{Modeling Market Shares of Competing (e)Care Providers 5}

is filled up completely by (part of) either his share of the inflow or the churn flow. The remainder is then distributed over the remaining providers of the tier by calculating new flow distributions based on the values offered and the market shares of the remaining competitors. By initially limiting the total inflow to the available capacity, the fact that the customers can always be distributed is assured.

The capacity model calculates capacity for each tier sequentially. It moves from high dependency levels to lower dependency levels (hence from Tier 3 to Tier 0 ) to give higher priority to high-dependent elderly people. This means that a lack in capacity of a traditional care provider cascades through the model from right to left (see graphical representation in Fig. 1) and can be a contributing factor to an eventual growing in popularity of eHealth solutions for the lower dependency level tiers.

\section{Simulation Results}

We ran simulations based on data for the Flemish area [7][8][9], for a 10 year period (going from 2010 till 2020). The figures illustrate results from our study. However, as the IBBT TranseCare project is still advancing and data is still being collected, refined as well as assessed by professionals from within the Flemish care sector, this might slightly influence the results presented below. Overall it is important to indicate the trend in which competition in the sector will evolve.

\subsection{Capacity}

The total elderly population in Flanders will increase in the upcoming years. This affects the total care sector, which is even today limited by capacity due to a lack of personnel and limitation in subsidized residential elderly care. This problem will furthermore increase in the future. Certainly for high-dependent capacity (service flats and retirement homes), places for new elderly are limited. The waiting lists today are very long [10] and no solution has been proposed, other than to build new service flats and retirement homes.

Fig. 2 shows the outcome from the study indicating the proportion of accepted versus denied capacity (waiting list). As explained in the previous section, people are distributed based on their dependency level in the different tiers (running from high to low dependency). Elderly people desperately in need of help will thus be distributed first. When capacity runs out, people are placed on a waiting list. Note that this is only the case for service flats and retirement homes in Tiers 3 and 2, as we assume that people from Tier 1 have equivalent care providers e.g. homecare. We see that in the beginning, the number of elderly being placed on the waiting list increases due to the current capacity problem in service flats and retirement homes. After year 6, this problem stabilizes at about $7 \%$ of people not being able to be helped. This problem is only situated in Tier 2, meaning that people with near constant (medical) attention 
6 Jan Van Ooteghem, Tom Tesch, Sofie Verbrugge, Ann Ackaert, Didier Colle, Mario Pickavet, Piet Demeester

(Tier 3) will always be helped. The waiting list problem is currently being "solved" by homecare (by professional or informal caregivers). However, homecare augmented with an eCarePlatform could be a (short term) solution for elderly with extended external attention before moving to a service flat or retirement home.

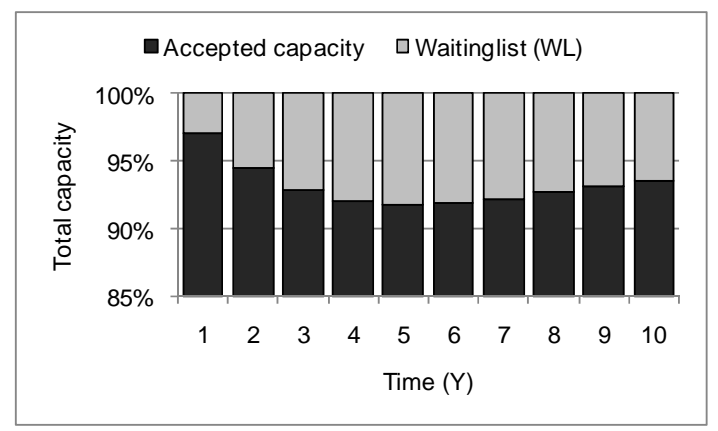

Fig. 2. Accepted capacity versus total capacity

\subsection{Market shares of competing care providers}

When we take a closer look at the market shares of the care providers for the different tiers, we can see the competition between providers offering equal services. The results are presented in Fig. 3 till Fig. 6, showing all care providers per tier (corresponding to Fig. 1), including waiting list (combined for service flats and retirement homes).

Tier 3 results show a full distribution of high-dependency elderly people to retirement homes $(\mathrm{RH})$. The waiting list (WL) remains zero over the time period considered, due to high mortality rate for Tier 3 elderly (24 months passage on average). For Tier 2, all capacity for service flats (SF) is taken up, due to their high value compared to retirement homes $(\mathrm{RH})$. The market share of retirement homes (RH) decreases due to limited capacity available after allocating Tier 3 elderly. Both these issues are reflected in the high waiting list (WL) market share. Solutions could be augmented homecare combined with an eCarePlatform or in worst case hospital admissions when required. In both Tier 1 and Tier 0 , two providers compete heavily due to equality in service. In Tier 1 this is homecare with (HC+eCP) and without (HC) eCarePlatform. The latter is considered to have a higher value (due to added value services), which results in the end in a higher market share. The market share of service flats (SF) and retirement homes (RH) is for Tier 1 non-existing due to no available capacity left after allocating Tier 3 and 2 elderly. Home care with or without eCarePlatform is a good alternative. For Tier 0, introducing the eCarePlatform (eCP) could add value to the life of people in good condition (e.g. for solving the problem of social isolation or communicating with family). 


\section{Modeling Market Shares of Competing (e)Care Providers 7}

The impact of the eCarePlatform could be seen in previous figures. The high value currently used for this provider in our analysis was based on several levels of benefits. First, an active (real time) patient monitoring leads to less medical visits with doctors or professional caretakers, being replaced by online guaranteed assistance. Second on the social level, this medium leads to a better communication with family, care takers, friends, etc. Third on the economic level, this could be a solution to keep control of the overall health care budget and personnel problem in the white sector.
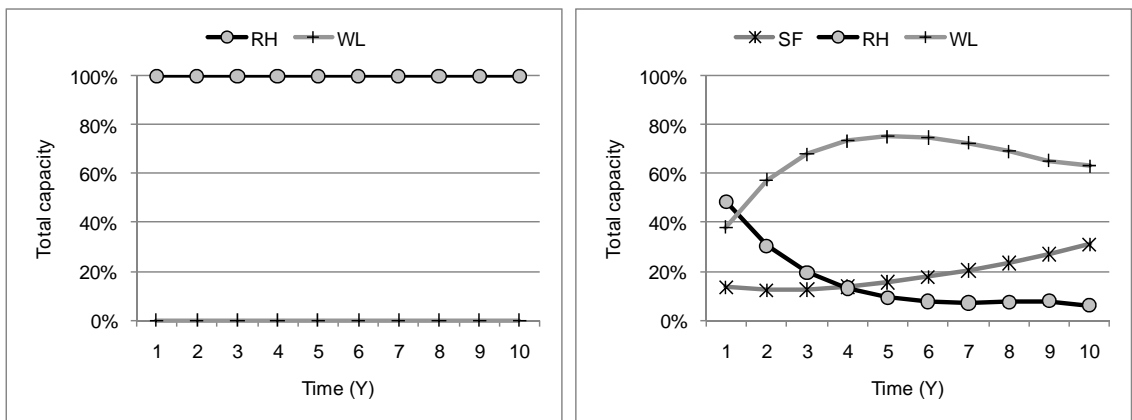

Fig. 3. Market shares care providers for Tier 3 Fig. 4. Market shares care providers for Tier 2
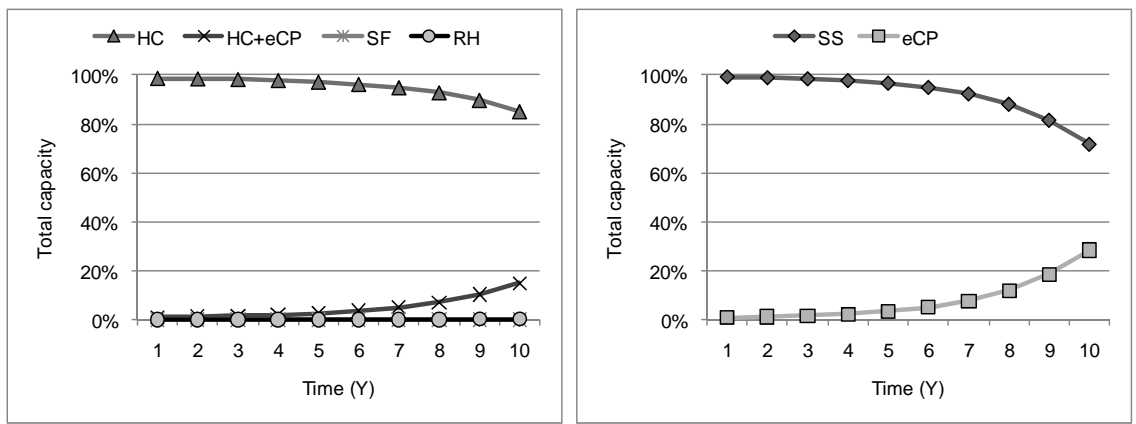

Fig. 5. Market shares care providers for Tier 1 Fig. 6. Market shares care providers for Tier 0

\section{Conclusion and future work}

In order to address the increasing costs of providing care to the growing group of elderly, introducing an eCare solution seems an obvious approach. The simulation model presented in this paper allows for forecasting evolution of market shares of competing care providers. Four tiers were defined and presented, based on the dependency level of the elderly, for which the market shares are determined, thereby taking into account available capacity of the different care providers, in- and outflow 
8 Jan Van Ooteghem, Tom Tesch, Sofie Verbrugge, Ann Ackaert, Didier Colle, Mario Pickavet, Piet Demeester

distribution between tiers and churn between providers within tiers. High-dependency elderly people (Tier 3) could always be allocated to retirement homes. However, there will always be a waiting list for people requiring extended external attention (Tier 2). Augmented home care combined with an eCarePlatform could be a solution to reduce the number of people on the waiting list. For Tier 1 and Tier 0 , competition exists between current care providers and providers introducing the eCarePlatform. The latter will gain market share as soon as efficiency and added value has been proven.

This study will be used furthermore as input for the techno-economic analysis of eCare platform business cases, based on eCare value network models. A quantitative study will be performed, making use of multi-actor analysis to calculate and evaluate the business case of each actor involved in the introduction of eHealth services.

\section{Acknowledgements}

This research was carried out as part of the IBBT TranseCare project (https://projects.ibbt.be/transecare/). This project is co-funded by the interdisciplinary research institute IBBT, by the IWT and by Televic, Androme, Custodix, SOL, WGK, In-HAM and UZGent. This work was carried out in the framework of the COST ISO605 Econ@Tel project.

\section{References}

[1] OECD (2009), OECD Regions at a Glance 2009, OECD, Paris

[2] European Commission (2009). “eHealth Benchmarking (Phase II)”. March 2009, http://ec.europa.eu/information_society/eeurope/i2010/benchmarking/

[3] European Commission (2009). "eHealth: a solution for European healthcare systems?”. The European Files, May-June 2009, Nr.17

[4] IBBT - Transecare project (https://projects.ibbt.be/transecare/)

[5] J. Van Ooteghem, S. De Maesschalck, K. Bamelis, J. Devos, P. Verhoeve, D. Colle, A. Ackaert, M. Pickavet, P. Demeester (2007). "An eHealth business model for independent living systems”. Proceedings (on CD-ROM) of e-Challenges 2007, ISBN 978-1-58603801-4, The Hague, October 24-26, 2007

[6] T. Tesch, P. T. Descamps, J. Van Hoecke, B. Leenknegt (2006). "Modeling Market Share Dynamics Using Weighted Averages and Value Elasticities: The M-WAVE Model”. CTTE 2006 conference proceedings

[7] FPS Economy - Statistics Division, http://statbel.fgov.be/

[8] E. Pelfrene (2005). “Ontgroening en vergrijzing in Vlaanderen 1990-2050”. Ministerie van de Vlaamse Gemeenschap, Administratie Planning en Statistiek

[9] Eurostat (2009). "Demographic Outlook - National reports on the demographic developments in 2007”. Publication date: January 29, 2009, ISSN 1977-0375

[10] Nieuwsblad (2008). "100.000 wachten op plekje in rusthuis“. Published on October 6, 2008. http://www.nieuwsblad.be/Article/Detail.aspx?articleID=qh21cj8m 